\title{
TONOGRAPHIC SURVEY OF THE CLOSE RELATIVES OF PATIENTS WITH CHRONIC SIMPLE GLAUCOMA*†
}

\author{
BY \\ T. GWILYM DAVIES \\ Whipps Cross Hospital, London
}

THAT glaucoma simplex may affect more than one member of a family is well known, but this would usually appear to occur in a sporadic fashion and have no hereditary significance. When true hereditary glaucoma occurs it is found in many members of the same family and is frequently traced over three or four generations. These families are, however, rare and have been well documented (François, 1961). Recently studies have been carried out on relatives of patients with glaucoma simplex in an effort to assess the hereditary element in the pathogenesis of the disease. The first reports by Biro (1951) and Kellerman and Posner (1955) were followed by tonographic surveys of the close relatives of glaucoma simplex patients, in particular by Becker, Kolker, and Roth (1960), Paterson (1961), and Miller (1961).

\section{Material}

In this investigation 62 patients with chronic simple glaucoma were selected from the records of Whipps Cross Hospital. The following criteria were used for selection:

(a) Field defect and cupped disc in one or both eyes unexplained except by the diagnosis of glaucoma.

(b) Open angles as seen by gonioscopy.

No account was taken of the initial or subsequent intra-ocular pressure in this selection.

\section{Method}

A family tree of the children and siblings of each patient was made and all subjects who lived within a reasonable distance of the hospital were then asked to attend for a single eye examination. From the 62 families selected, children or siblings or both were seen from $\mathbf{4 2}$ families, and the examination included the following:

(1) Corrected visual acuity.

(2) Estimation of depth of anterior chamber (i.e. shallow, medium, or deep) together with a general slit-lamp examination.

(3) Assessment of optic discs.

(4) Applanation tonometry of both eyes with a Goldmann applanation tonometer.

(5) Tonography of both eyes with a Schwarzer electronic recording tonometer. Coefficient of outflow facility (c) was estimated using tonographic tables for eyes with average scleral rigidity. The ratio $\mathbf{P}_{\mathrm{o}} / \mathbf{c}\left(\mathbf{P}_{\mathbf{o}}=\right.$ intra-ocular pressure and $\mathbf{c}=$ coefficient of outflow facility $)$ was calculated. This measurement was introduced by Leydhecker (1958a) to distinguish between normal and early glaucomatous eyes and a value above 100 is now generally accepted as being abnormal.

* Received for publication September 22, 1966

† Address for reprints: Royal Free Hospital, Gray's Inn Rd., London, W.C.1. 


\section{Subjects Examined}

\section{Results}

(a) Siblings. -56 siblings were invited for examination and 31 attended from nineteen families. The male : female ratio of those examined is similar to that for the whole group. There was a preponderance of younger subjects examined, the average age being $60 \cdot 2$ years and that of the subjects not seen 66.0 years. There were only two subjects in the 40 to 49-year age group and these were excluded. The findings are shown in Table I.

TABLE I

Results in 31 Siblings of Glaucoma Patients

\begin{tabular}{l|c|c|c|c}
\hline \multicolumn{2}{l|}{} & $50-59$ & $60-69$ & $70-79$ \\
\hline \multicolumn{2}{l|}{ Age Group (yrs) } & 14 & 10 & 5 \\
\hline \multicolumn{2}{l|}{ Average $\mathrm{P}_{\mathrm{o}} / \mathrm{c}$} & $68 \cdot 0$ & 78.9 & 113.0 \\
\hline \multirow{2}{*}{$\mathrm{P}_{\mathrm{o}} / \mathrm{c}>100$} & No. & 1 & 5 & 4 \\
\cline { 2 - 5 } & Per cent. & 7 & 50 & 80 \\
\hline
\end{tabular}

(b) Children.- -87 children were invited for examination and 61 attended from 34 families. A greater proportion of females was examined than males. The average age of those who failed to attend was higher than that of those examined. The findings are shown in Table II.

TABLE II

Results in 61 Children of Glaucoma Patients

\begin{tabular}{l|c|c|c|c|c|c|c}
\hline \multicolumn{2}{l|}{ Age Group (yrs) } & $10-19$ & $20-29$ & $30-39$ & $40-49$ & $50-59$ & $60-69$ \\
\hline \multicolumn{2}{l|}{ No. of Subjects } & 4 & 8 & 12 & 22 & 10 & 5 \\
\hline \multicolumn{2}{l|}{ Average $P_{\mathrm{o}} / \mathrm{c}$} & $64 \cdot 3$ & $62 \cdot 1$ & $70 \cdot 0$ & $69 \cdot 8$ & $73 \cdot 1$ & $91 \cdot 8$ \\
\hline \multirow{2}{*}{$P_{\mathrm{o}} / \mathrm{c}>100$} & No. & 1 & 0 & 3 & 4 & 3 & 3 \\
\cline { 2 - 8 } & Per cent. & 25 & 0 & 25 & 18 & 30 & 60 \\
\hline
\end{tabular}

(c) Controls.-50 patients were selected from the surgical, E.N.T., and orthopaedic wards who had been admitted with fractures or minor surgical conditions. One eye only was examined, the choice of left or right being a random selection. All eyes were normal and no subject had a family history of glaucoma. The $P_{o} / c$ is shown in Table III. No control eye was found to have a $P_{o} / c>100$.

TABLE III

Results in 50 CONTROLS

\begin{tabular}{l|c|c|c|c|c}
\hline Age Group (yrs) & $30-39$ & $40-49$ & $50-59$ & $60-69$ & $70-79$ \\
\hline No. of Eyes & 10 & 10 & 10 & 10 & 10 \\
\hline Average Po/c & $49 \cdot 2$ & $45 \cdot 4$ & $47 \cdot 2$ & $60 \cdot 2$ & $67 \cdot 7$ \\
\hline
\end{tabular}

\section{Water-Drinking and Steroid Provocative Tests with Tonography}

All siblings and children with $P_{0} / c>100$ in one or both eyes were invited to attend for a further examination, which consisted of:

(a) Central and peripheral fields with a Goldmann perimeter.

(b) Water-drinking provocative test followed $\mathbf{3 0}$ minutes later by tonography. 
(c) Steroid provocative test. For a period of 3 weeks gutt. Disodium Phosphate Betamethasone 0.1 per cent. was instilled four times daily into one eye, and gutt. normal saline into the fellow eye. Neither the patient nor the examiner knew which eye had been treated with steroids. At the end of 3 weeks further applanation tonometry and tonography were done. The results are shown in Table IV.

TABLE IV

Results of Further Examination of Siblings and Children

\begin{tabular}{|c|c|c|c|c|c|c|c|}
\hline \multirow{3}{*}{ Subjects } & \multirow{2}{*}{\multicolumn{2}{|c|}{$\mathrm{P}_{\mathrm{o}} / \mathrm{c}>100$}} & \multirow{2}{*}{$\begin{array}{l}\text { No. } \\
\text { Examined }\end{array}$} & \multicolumn{2}{|c|}{$\begin{array}{c}\text { Average Rise in I.O.P. } \\
(\mathrm{mm} . \mathrm{Hg})\end{array}$} & \multicolumn{2}{|c|}{$\begin{array}{l}\text { Average per cent. Rise in } \\
\mathbf{P}_{0} / \mathbf{c}\end{array}$} \\
\hline & & & & After water & After Steroid & After water & After Steroid \\
\hline & No. & Per cent. & \multirow[b]{2}{*}{8} & \multirow[b]{2}{*}{$3 \cdot 3$} & \multirow[b]{2}{*}{$3 \cdot 8$} & \multirow[b]{2}{*}{$16 \cdot 7$} & \multirow[b]{2}{*}{16.9} \\
\hline Siblings & 10 & 32 & & & & & \\
\hline Children & 14 & 23 & 10 & $3 \cdot 5$ & $4 \cdot 7$ & $1 \cdot 8$ & $41 \cdot 3$ \\
\hline
\end{tabular}

Individual cases were classified into abnormal $\mathbf{P}_{\mathbf{o}} / \mathrm{c}$, suspect and definite glaucoma simplex. The criteria for this was as follows:

(a) Abnormal $P_{o} / c: P_{0} / c>100$

(b) Suspect Glaucoma Simplex: Any two of the following:

(i) $\mathrm{P}_{\mathrm{o}}>20 \mathrm{~mm} . \mathrm{Hg}$

(ii) $\mathrm{c}<0 \cdot 12$

(iii) Water-drinking test $>6 \mathrm{~mm}$. $\mathrm{Hg}$

(c) Definite Glaucoma Simplex: Visual field loss with cupped disc.

All pressure readings are by applanation tonometry.

Siblings

(a) Abnormal $P_{o} / c$ : ten (32 per cent.)

(b) Suspect Glaucoma Simplex: two (6 per cent.)

(1) 48-year-old female (Her twin brothers had glaucoma simplex).

\begin{tabular}{l|c|c|c|c|c}
\hline \multicolumn{1}{c|}{ Eye } & $\mathbf{P}_{\mathrm{o}}$ & $\mathrm{c}$ & $\mathbf{P}_{\mathrm{o}} / \mathrm{c}$ & Water & Steroid \\
\hline $\begin{array}{l}\text { Right } \\
\text { Left }\end{array}$ & $\begin{array}{c}\mathbf{2 1} \\
\mathbf{2 3}\end{array}$ & $\begin{array}{c}\mathbf{0} \cdot 24 \\
\mathbf{0} \cdot 12\end{array}$ & $\begin{array}{c}\mathbf{8 8} \\
\mathbf{1 9 2}\end{array}$ & $\begin{array}{c}\text { negative } \\
\text { negative }\end{array}$ & $\begin{array}{c}\text { negative } \\
\text { negative }\end{array}$ \\
\hline
\end{tabular}

(2) 72-year-old male.

\begin{tabular}{l|c|c|c|c|c}
\hline \multicolumn{1}{c|}{ Eye } & Po & $\mathrm{c}$ & Po/c & Water & Steroid \\
\hline $\begin{array}{l}\text { Right } \\
\text { Left }\end{array}$ & 20 & $\begin{array}{c}0 \cdot 24 \\
0 \cdot 17\end{array}$ & $\begin{array}{r}83 \\
106\end{array}$ & $\begin{array}{c}+5 \mathrm{~mm} . \mathrm{Hg} \\
+6 \mathrm{~mm} . \mathrm{Hg}\end{array}$ & $+5 \mathrm{~mm} . \mathrm{Hg}$ \\
\hline
\end{tabular}

(c) Definite Glaucoma Simplex: two (6 per cent.)

(1) 56-year-old male. Under treatment at another hospital. Right visual field down to 20 degrees. Left visual field restricted above. Bilateral cupping of discs. Right trephine and left iris inclusion, 1961.

(2) 72-year-old female. Early cupping left disc with superior arcuate scotoma and early upper nasal peripheral field loss.

\begin{tabular}{l|c|c|c|c|c}
\hline \multicolumn{1}{c|}{ Eye } & $\mathbf{P}_{\mathrm{o}}$ & $\mathrm{c}$ & $\mathbf{P}_{\mathrm{o}} / \mathrm{c}$ & Water & Steroid \\
\hline $\begin{array}{l}\text { Right } \\
\text { Left }\end{array}$ & 20 & $\mathbf{0 . 0 8}$ & $\mathbf{2 5 0}$ & negative & $+7 \mathrm{~mm} . \mathrm{Hg}$ \\
\hline
\end{tabular}




\section{Children}

(a) Abnormal $P_{o} / c$ : fourteen (23 per cent.)

(b) Suspect Glaucoma Simplex: three (5 per cent.)

(1) 64-year-old female.

\begin{tabular}{l|c|c|c|c|c}
\hline \multicolumn{1}{c|}{ Eye } & $\mathbf{P}_{\mathrm{o}}$ & $\mathrm{c}$ & $\mathbf{P}_{\mathrm{o}} / \mathrm{c}$ & Water & Steroid \\
\hline $\begin{array}{l}\text { Right } \\
\text { Left }\end{array}$ & 20 & $\begin{array}{l}0.16 \\
\mathbf{0}\end{array}$ & $\begin{array}{c}125 \\
150\end{array}$ & not done & not done \\
\hline
\end{tabular}

(2) 48-year-old male. As well as his father, his father's sister has glaucoma.

\begin{tabular}{l|c|c|c|c|c}
\hline \multicolumn{1}{c|}{ Eye } & $P_{\mathrm{o}}$ & $\mathrm{c}$ & $\mathrm{P}_{\mathrm{o}} / \mathrm{c}$ & Water & Steroid \\
\hline $\begin{array}{l}\text { Right } \\
\text { Left }\end{array}$ & $\mathbf{1 8}$ & $\begin{array}{c}\mathbf{0} \cdot 31 \\
\mathbf{0} \cdot 12\end{array}$ & $\begin{array}{r}58 \\
\mathbf{1 5 8}\end{array}$ & $\begin{array}{c}+7 \mathrm{~mm} . \mathrm{Hg} \\
+8 \mathrm{~mm} . \mathbf{H g}\end{array}$ & $+5 \mathrm{~mm} . \mathrm{Hg}$ \\
\hline
\end{tabular}

(3) 43-year-old female. Niece with juvenile glaucoma, but the niece's mother had normal tonography and intra-ocular pressure.

\begin{tabular}{c|c|c|c|c|c}
\hline \multicolumn{1}{c|}{ Eye } & $P_{0}$ & $c$ & $P_{o} / \mathrm{c}$ & Water & Steroid \\
\hline $\begin{array}{c}\text { Right } \\
\text { Left }\end{array}$ & 20 & $\begin{array}{c}0 \cdot 18 \\
\mathbf{0}\end{array}$ & $\begin{array}{c}111 \\
180\end{array}$ & $\begin{array}{c}+5 \mathrm{~mm} . \mathrm{Hg} \\
+4 \mathrm{~mm} . \mathbf{H g}\end{array}$ & negative \\
\hline
\end{tabular}

(c) Definite Glaucoma Simplex: Nil.

\section{Discussion}

It is clearly demonstrated that the $P_{o} / c$ ratio is higher in the relatives of patients with glaucoma simplex than in the controls (Fig. 1). It is difficult to make comparisons with the results of other surveys since different criteria were used for selecting the subjects and the age distributions vary. Bearing these differences in mind, the results are found to correspond quite closely. The results of the present survey are given in brackets. Paterson, in fifty siblings aged 40-60, found 38 per cent. with $P_{o} / c>100$ (32 per cent. in 31 siblings aged 50-75). Miller, in 75 children aged 15-60, found 41.9 per cent. with $P_{o} / c>100$ (23 per cent. in 61 children aged 16-62). Becker and others, selecting only those families with two or more cases of glaucoma, found in 110 combined siblings and children that 24.7 per cent. had a $P_{o} / c>100$ (26.1 per cent. in 91 siblings and children).

When the average $P_{o} / c$ is plotted against age in decades (Fig. 1, opposite), it is seen to rise with advancing age in all three groups. The curve, after being initially flat, rapidly steepens at between 55 and 65 years. The average $P_{o} / c$ of the glaucoma relatives is approximately 40 per cent. greater than that of the controls in corresponding age groups. Also the average $P_{0} / c$ of the children is higher than that of the siblings in corresponding age groups. This may be expected, since one glaucoma patient has been removed from each of the sibling family groups, whereas all the theoretically potential glaucoma cases are still present in the child groups, and this might be expected to raise the average $P_{o} / c$.

When the two components of the $P_{0} / c$ ratio in the glaucoma relatives were analysed in age groups (Figs 2 and 3), similar curves were obtained for both $P_{0}$ and $c, P_{0}$ increasing and $\mathrm{c}$ decreasing with age. The increase in $\mathrm{P}_{\mathrm{o}}$ and the decrease in $\mathrm{c}$ becomes more marked 


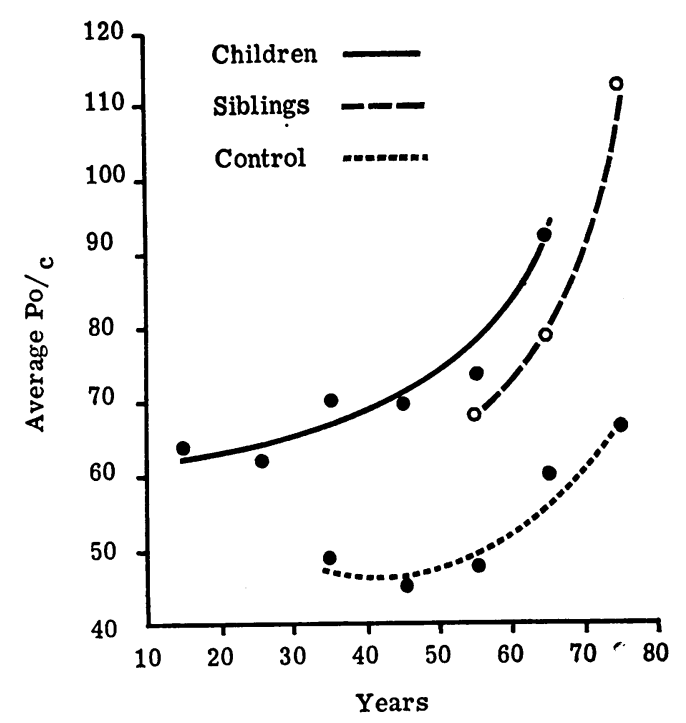

Fig. 1.-Average $P_{0} / c$ in child, sibling, and control groups plotted against age.

FIGs 2 and 3.-Average $P_{o}$ and $c$ values of glaucoma relatives and controls plotted against age.
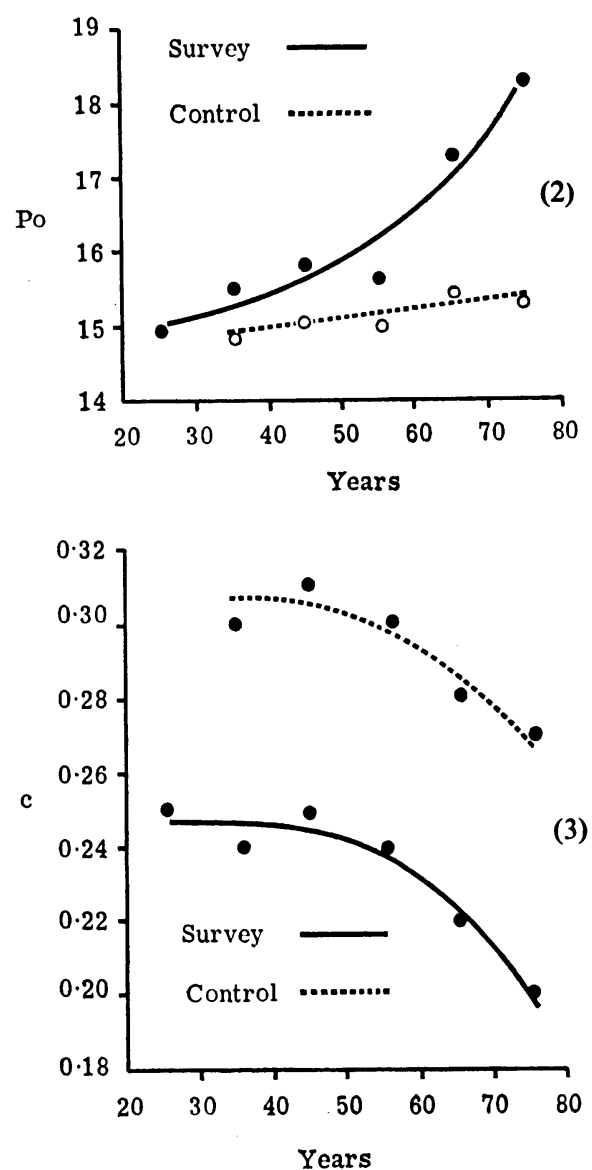

at 55-65 years. In the controls the fall in the c curve does steepen at 55-65 years, whereas the $P_{0}$ shows only a gradual linear rise which agrees with the findings of large surveys of intra-ocular measurements in the general population (Eggink, 1962). It is known that a decrease in the outflow facility is an accompaniment of ageing and that this decrease is more rapid in late middle life. It is seen that the decrease in the outflow facility is more marked in the glaucoma relatives than in the controls, and this is accompanied with a steeply rising $P_{0}$. This is resisted in the normal subjects and the $P_{0}$ rise continues to be gradual and linear.

Frequency distribution curves were plotted (Figs. 4 and 5, opposite) to discover whether the study group consisted of two populations or there was a general rise in $P_{0}$ and a fall in $c$. The $P_{0}$ curve did suggest that there were two populations. The greatest frequency in both control and study groups was $P_{0} 14 \mathrm{~mm}$. $\mathrm{Hg}$, with a secondary rise in frequency at $17-18 \mathrm{~mm}$. Hg. This persistence of the curve into the higher pressure readings has been found in large-scale surveys of measurements of intra-ocular pressure in the general population. In the Oxford survey (Luntz, Sevel, and Lloyd, 1965), this "tail" of high pressure readings was reduced but still persisted when subjects with a family history of glaucoma were excluded. In the present study groups the extent of this "tail" is very much larger and extends further into the higher intra-ocular pressure readings than in the 

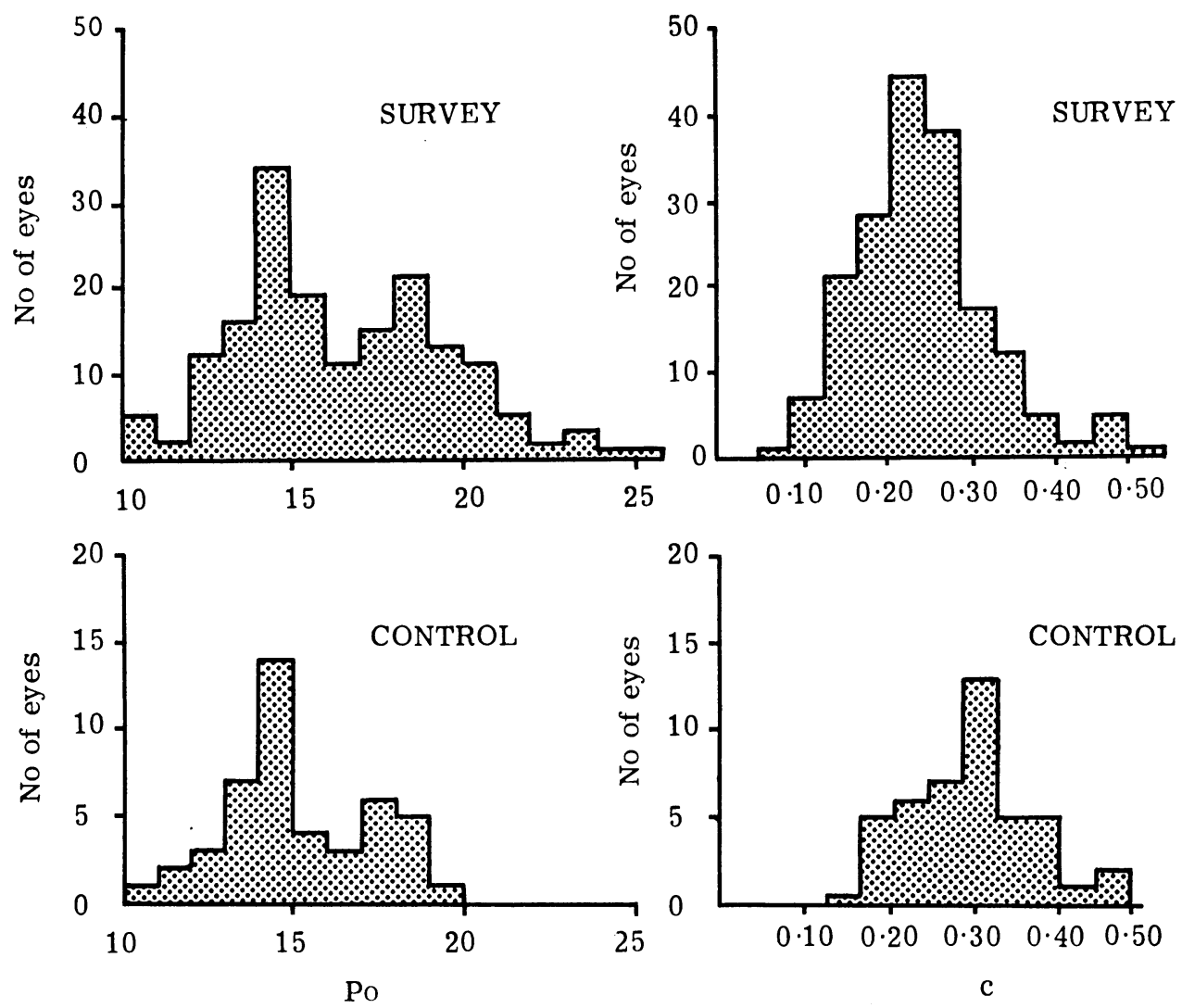

FIGs 4 and 5.-Frequency distribution curves of $P_{0}$ and $c$ in survey and control groups.

control group. The c frequency distribution curve showed only a general shift from $0 \cdot 30$ in the controls to 0.24 in the study group.

No correlation was found when comparing effects of the water-drinking provocative test and the application of local steroids in producing a rise in the intra-ocular pressure. If an eye had previously shown a significant rise in intra-ocular pressure after the waterdrinking test, there would be only a 50 per cent. chance of its producing a significant rise after 3 weeks' application of gutt. Betamethasone $0 \cdot 1$ per cent. This result might be expected, since the effectiveness of the water-drinking provocative test depends on the degree of haemodilution produced (Drance, 1958) and negative results are found in 35-45 per cent. of proven cases of glaucoma simplex. However, even with these small numbers, a striking difference was noticed in the effect of water-drinking and of steroids on average $P_{o} / c$ ratios when analysed by age (Fig. 6, overleaf). The water-drinking test produced the maximum increase in the $P_{0} / c$ ratio in the older age group whereas steroids had their greatest effect on the younger age group.

Further supporting evidence that glaucoma simplex has a hereditary pathogenesis is shown by the incidence of glaucoma simplex among the siblings. A history of eye disease among 114 siblings over 45 years of age from 51 families revealed nine cases ( 7.9 per cent.) of chronic simple glaucoma. All the cases had the diagnosis confirmed by the hospital 


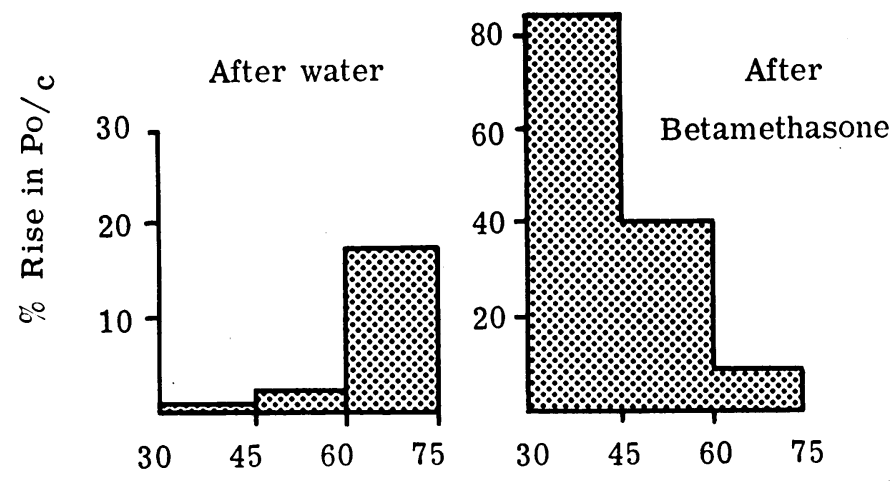

Fig. 6.-Average per cent. rise in $P_{0} / c$ ratio after water-drinking and steroid provocative tests, expressed in 15-year age groups.

caring for the patient and each case had visual field loss and cupped optic discs. This compares with an incidence varying between 1.5 and 2 per cent. of glaucoma in the general population over the age of 45 years (Leydhecker, 1958b). Moreover, this diagnosis of glaucoma was made on the presence of raised intra-ocular pressure, decreased outflow facility, and a positive provocative test. When glaucoma is defined as consisting of field loss and cupped optic discs, the incidence could be expected to be much lower. The fact that a percentage of glaucoma relatives have an elevated intra-ocular pressure and a decreased coefficient of outflow is of clinical importance only if it results in the early detection of glaucoma simplex. That these subjects are pre-glaucomatous will be demonstrated if they show the generally accepted signs of glaucoma, i.e. persistently raised intra-ocular pressure with field loss and cupped optic discs; these may take many years to develop. It may be possible to obtain further evidence to support this hypothesis-that a percentage of the close relatives of glaucoma patients are pre-glaucomatous-before these suspects reach an age when the glaucoma becomes readily recognized. Of the 31siblings examined only five were over 70 years of age and the majority of the siblings still alive and over 70 years were not seen. Glaucoma is not known to shorten or prolong life and therefore these older siblings may be taken as representing their younger siblings when and should they reach this age. Assuming $P_{o} / c>100$ to be the dividing line, then approximately 30 per cent. of the siblings were pre-glaucomatous and a similar proportion of their older siblings should have developed signs of the disease. This hypothetical 30 per cent. incidence of glaucoma corresponds with the 6 per cent. discovered in the siblings examined and the 7.9 per cent. of known glaucoma in the entire sibling population of the survey. Whether a further "hidden" 20 per cent. of glaucoma simplex exists among the siblings is to be tested by examining in their homes all the siblings over 70 years of age and the results will be reported later.

\section{Summary}

Tonography was performed on 31 siblings and 61 children of patients with glaucoma simplex. A control survey was made on fifty normal subjects. The average $P_{o} / c$ ratio was higher in the survey group than in the controls. $P_{\mathrm{o}} / \mathrm{c}>100$ was found in 32 per cent. of the siblings and 23 per cent. of the children. Incidence of definite glaucoma was 6 per cent. of the siblings examined. The percentage of known glaucoma among the entire sibling population of the survey was 7.9 per cent. No correlation was found between the water-drinking and steroid provocative tests. It is suggested that the decrease in the outflow facility which accompanies ageing produces a rise in the intra-ocular pressure in a 
proportion of glaucoma relatives and that this is not seen in subjects with no family history of glaucoma.

This work was financed by the Research Committee of the North East Regional Hospital Board.

I wish to thank Mr. M. Klein for his constant help and encouragement; Mr. J. S. Conway for allowing his patients to be included in the survey; Mr. J. D. Abrams for his critical advice in preparing the paper. My appreciation is due to Mr. F. A. D. Allen, Chief Pharmacist to the Whipps Cross Hospital Group, and particularly to his deputy, Miss P. Stone, for controlling the steroid trial. I am most grateful to Mrs. G. D. Quant, the research secretary, for her devoted and painstaking work. The illustrations were provided by Mr. T. Tarrant, Institute of Ophthalmology. Finally, I am indebted to all the relatives and controls who volunteered to take part in the survey.

\section{REFERENCES}

BeCKer, B., Kolker, A. E., and Roth, F. D. (1960). Amer. J. Ophthal., 50, 557.

BIRó, I. (1951). Ophthalmologica (Basel), 122, 228.

DRANCE, S. M. (1958). Trans. ophthal. Soc. U.K., 78, 565.

EGGINK, E. D. (1962). Ophthalmologica (Basel), 143, 113.

Françors, J. (1961). "Heredity in Ophthalmology", pp. 225-238. Mosby, St. Louis.

Kellerman, L., and Posner, A. (1955). Amer. J. Ophthal., 40, 681.

LEYDHECKER, W. (1958). Trans. ophthal. Soc. U.K., 78, 553. , AkiYama, K., and NeumanN, H. G. (1958). Klin. Mbl. Augenheilk., 133, 662.

LunTz, M. H., Sevel, D., and Lloyd, J. P. F. (1965). Brit. J. Ophthal., 49, 128.

MILLER, S. (1961). Trans. ophthal. Soc. U.K., 81, 577.

PATERSON, G. (1961). I lbid., 81, 561. 